\title{
Symptomatic and silent myocardial ischaemia in hypertensive patients with left ventricular hypertrophy
}

Stuart D Pringle, Francis G Dunn, Ann C Tweddel, William Martin, Peter W Macfarlane, James H McKillop, A Ross Lorimer, Stuart M Cobbe

Abstract

Objective-To assess the prevalence of symptomatic and silent myocardial ischaemia in patients with hypertensive left ventricular hypertrophy.

Design-Cross sectional study.

Setting-University department of medical cardiology.

Patients-90 patients $(68$ men and 22 women; mean age 57 (range 25 to 79)) with left ventricular hypertrophy due to essential hypertension.

Interventions -48 hour ambulatory ST segment monitoring (all patients), exercise electrocardiography $(n=79)$, stress thallium scintigraphy $(n=80)$, coronary arteriography $(n=35)$.

Results -43 patients had at least one episode of ST segment depression on ambulatory electrocardiographic monitoring. The median number of episodes was 16 (range 1 to 84 ) with a median duration of 8.6 (range 2 to 17) min. Over $90 \%$ of these episodes were clinically silent. 26 patients had positive exercise electrocardiography and 48 patients had reversible thallium perfusion defects despite chest pain during exercise in only five patients. 18 of the 35 patients who had coronary arteriography had important coronary artery disease. Seven of these patients gave no history of chest pain.

Conclusions-Symptomatic and silent myocardial ischaemia are common in hypertensive patients with left ventricular hypertrophy, even in the absence of epicardial coronary artery disease.

Department of Medical Cardiology, Royal Infirmary, Glasgow

$S$ D Pringle

A C Tweddel

W Martin

P W Macfarlane

A R Lorimer

$S$ M Cobbe

Department of Medical Cardiology, Stobhill General Hospital, Glasgow F G Dunn

University

Department of Medicine, Royal Infirmary, Glasgow

J H McKillop

Correspondence to Dr Stuart D Pringle, Cardiology Department, Royal Infirmary, 1 Lauriston Place, Edinburgh EH3 9YW.

Accepted for publication 12 September 1991
There is now considerable epidemiological evidence that hypertensive patients with left ventricular hypertrophy are at increased risk of all manifestations of coronary heart disease. ${ }^{1-3}$ Myocardial infarction and stable and unstable angina are all more common in these patients. This relation persists even after correction for the contribution of hypertension and other risk factors for atherosclerosis. ${ }^{23}$ The presence of electrocardiographic left ventricular hypertrophy carries a prognosis similar to that of electrocardiographic evidence of a previous myocardial infarction. ${ }^{3-5}$

Despite the large number of epidemiological studies there are few data on the objective assessment of myocardial ischaemia in individual patients with hypertensive left ventricular hypertrophy. We have shown previously that patients with hypertensive left ventricular hypertrophy may have thallium perfusion abnormalities or coronary artery disease and yet be symptom free. ${ }^{6}$ Because chest pain was an exclusion criterion for the previous study, however, the patients were not representative of all patients with hypertensive left ventricular hypertrophy. We therefore conducted the present study to assess prevalence of symptomatic and asymptomatic myocardial ischaemia in hypertensive patients with left ventricular hypertrophy attending a hospital based hypertension clinic and to determine the best non-invasive method to identify prognostically important coronary artery disease in these patients.

\section{Patients and methods}

We recruited 90 consecutive patients ( 68 men) (mean age 57 (range 25 to 79 ) years) who agreed to be in the study and fulfilled the following criteria:

(a) they had essential hypertension-secondary hypertension was excluded by clinical evaluation, routine biochemical screening, chest $x$ ray, and, where indicated, intravenous pyelography.

(b) they had the electrocardiographic pattern of left ventricular hypertrophy and strain.

The study was approved by the ethics committee of Glasgow Royal Infirmary. The patients provided written informed consent for the invasive procedures and verbal consent for the non-invasive investigations.

\section{ELECTROCARDIOGRAPHY}

Twelve lead electrocardiograms were recorded with the Glasgow CARE (computer assisted reporting of electrocardiograms) system. ${ }^{7}$ For the purposes of this study left ventricular hypertrophy and strain were defined as ST segment depression and $T$ wave inversion of $0.1 \mathrm{mV}$ or more in $\mathrm{I}$, aVL, V5, or V6 in the presence of voltage criteria (SV1 + RV5 $>3.5$ $\mathrm{mV}$ ) for left ventricular hypertrophy.

ECHOCARDIOGRAPHY

We assessed the degree of left ventricular hypertrophy by echocardiography performed with an Advanced Technology Laboratories Ultramark 8 mechanical scanner with a $3 \mathrm{MHz}$ transducer. Left ventricular mass was calculated by an anatomically validated method. ${ }^{8}$

\section{EXERCISE ELECTROCARDIOGRAPHY}

The patients exercised on a Tunturi bicycle 
ergometer. The workload was increased by 50 W every 3 minutes up to a symptom limited maximum. At the end of each stage and at maximum exercise blood pressure was measured by cuff sphygmomanometer, a simultaneous 12 lead electrocardiogram was recorded, and the heart rate was estimated from the $R R$ interval. We calculated the maximal oxygen uptake from the maximum load during the final stage of exercise using nomograms from normal subjects ${ }^{9}$ and patients with cardiovascular disease. ${ }^{10}$ The double product was calculated from the product of systolic pressure at peak exercise and maximal heart rate.

The exercise electrocardiograms were recorded at a paper speed of $25 \mathrm{~mm} / \mathrm{s}$ on a SiemensElema Mingocard 3. ST segment depression was defined as horizontal or down sloping ST segment depression of $0.1 \mathrm{mV}$ or greater at 80 ms after the J point. ${ }^{11}$ In view of the high rate of electrocardiographic false positives in patients with resting ST-T wave changes ${ }^{12}$ we only considered additional ST segment depression of $0.2 \mathrm{mV}$ or more compared with the resting depression as significant in patients with left ventricular hypertrophy and strain. ${ }^{13}$ The number of leads showing significant ST segment depression was also counted. In patients with abnormal resting electrocardiograms another method which may be useful is the measurement of changes in $\mathbf{R}$ wave amplitude during exercise. ${ }^{12}$ The amplitudes of the $R$ waves of five consecutive complexes at rest and peak exercise were therefore measured, with an abnormal $\mathbf{R}$ wave response defined as one in which there was no change or an increase in the amplitude with exercise. ${ }^{14}$

\section{AMBULATORY ST SEGMENT MONITORING} Ambulatory electrocardiograms were recorded for 48 hours with a Medilog II FM recorder and analysed by an experienced technician using a computer assisted technique. ${ }^{15}$ Two leads were recorded, CM5 on channel 1 and a V2 type lead on channel 2. The ST segment shifts were measured at $80 \mathrm{~ms}$ after the J point. Significant ST depression was defined as horizontal or downsloping ST depression of greater than $0.1 \mathrm{mV}$ that persisted for more than one minute. ${ }^{16}$ In our study, the resting ST-T wave changes of all patients (with left ventricular hypertrophy and strain) meant that channel 1 (CM5) would not appear abnormal under normal circumstances. Therefore the criteria were modified so that a positive result was recorded only if there was additional ST depression of more than $0.2 \mathrm{mV}$ compared with the resting changes. In the system used, the computer analysis provides a minute by minute trend of the ST segment shifts and this was scanned manually for periods of ST segment depression fulfilling the criteria. An episode was counted only if ST segment depression was detected by review of these trends and confirmed on hardcopy printout. The total duration of ST segment depression was calculated to the nearest minute from the computer summary.
STRESS THALLIUM SCINTIGRAPHY

Thallium-201 chloride $(80 \mathrm{MBq})$ was injected at peak exercise via an indwelling antecubital cannula 30 to $60 \mathrm{~s}$ before the end of symptom limited maximal exercise. Images were acquired in list mode for $300 \mathrm{~s}$ for each projection and electrocardiographically gated. Data were acquired in the anterior, $45^{\circ}$ left anterior oblique and $75^{\circ}$ left anterior oblique projections by a mobile gamma camera (General Electric) fitted with a high sensitivity collimator interfaced to a dedicated computer. The images were then put into an eight frames per cycle gated study format representative of the cardiac cycle. Beats deviating by $20 \%$ or more of the mean RR interval were excluded. Redistribution images were obtained four hours later in the same fashion.

The studies were analysed by visual inspection of the gated study by two experienced observers. The ventricle was divided into five segments in each projection. A perfusion defect was deemed to be present if the predominant colour in that segment was reduced by at least two of the 16 colour levels. A reversible perfusion defect was defined as one that showed partial or complete resolution on the redistribution images compared with the post-stress images. ${ }^{17}$ Images that did not change significantly were classified as fixed defects.

\section{REPRODUCIBILITY OF INTERPRETATION OF THALLIUM SCINTIGRAPHY}

The intraobserver and interobserver variability was assessed for 50 of the thallium scans. The images were reviewed independently by two observers (SP and WM). Each observer completed a pre-printed report form representing the six images from each patient (three immediately after exercise and three redistribution images). After completion of the reports the number of regions in which there was a disagreement was compared firstly between the observers and secondly between the same observer on two different occasions.

In total there were $\mathbf{1 5 0 0}$ regions in these $\mathbf{5 0}$ patients and a disagreement in perfusion was present in 33 regions between observers and in 37 between the first and second review of the same scan. Thus the interobserver reproducibility was $\mathbf{9 7 \cdot 8 \%}$ and intraobserver reproducibility was $97 \cdot 5 \%$.

\section{CORONARY ARTERIOGRAPHY}

We considered the desirability of coronary arteriography for each patient bearing in mind their age, general health, and coexistent medical problems. Sixty two patients were considered suitable and 35 agreed to undergo coronary arteriography. The remaining 27 patients declined mainly because of a reluctance to be admitted to hospital rather than anxiety about the procedure. There was no conscious bias towards recruiting patients with chest pain for coronary arteriography. Indeed the patients who did not have invasive invesigations tended to be older and therefore might have been expected to have more coronary artery disease.

The femoral artery was cannulated by the 
Table 1 Clinical characteristics of the patients

\begin{tabular}{lcl}
\hline Age (y) & \multicolumn{3}{c}{57 (range 25 to 79) } \\
Sex (men:women) & $68: 22$ & \\
Angina & 21 & \\
Previous MI & 5 & \\
SBP (mm Hg) & 155 & $(28)$ \\
DBP (mm Hg) & 89 & $(15)$ \\
Duration of HT (y) & $7 \cdot 4$ & $(8 \cdot 0)$ \\
LVMI (g/m ${ }^{2}$ ) & $196 \cdot 4$ & $(50 \cdot 5)$ \\
Drug therapy: & & \\
Thiazides (No (\%)) & 34 & $(38)$ \\
$\beta$ Blockers (No (\%)) & 38 & $(42)$ \\
Ca antag (No (\%)) & 40 & $(44)$ \\
ACE I (No (\%)) & 23 & $(25)$ \\
Mean No of drugs & $2 \cdot 51$ & $(1 \cdot 4)$ \\
\hline
\end{tabular}

MI, myocardial infarction; SBP, systolic blood pressure; DBP, diastolic blood pressure; HT, hypertension; LVMI, left ventricular mass index; Ca antag, calcium antagonists; ACE I, angiotensin converting enzyme inhibitors.

Results are expressed as mean (SD) unless otherwise stated.

Table 2 Exercise electrocardiography $(n=79)$

\begin{tabular}{lrl}
\hline Result & $n$ & $\begin{array}{l}\text { No with } \\
\text { chest pain }\end{array}$ \\
\hline $\begin{array}{l}\text { Additional ST segment depression } \\
(>0 \cdot 2 \text { mV) }\end{array}$ & 26 & 5 \\
$\begin{array}{l}\text { Increased number of leads showing } \\
\quad \text { TT segment depression }\end{array}$ & 14 & 2 \\
Abnormal R wave response & 40 & 2 \\
Two positive criteria & 21 & 3 \\
Three positive criteria & 2 & 0 \\
Exercise induced ventricular & 12 & 0 \\
$\quad$ ectopic beats & 12 & 0 \\
$\quad$ dermalisation of ST segment & 22 & 0 \\
No exercise induced ECG changes & & \\
\hline
\end{tabular}

Seldinger technique under local anaesthetic and the coronary arteries were injected selectively. The films were analysed in detail by at least two observers. A vessel was defined as significantly diseased where luminal diameter was reduced by more than $50 \%$.

\section{STATISTICAL ANALYSIS ${ }^{18}$}

To compare the two groups of data we used a two sample $t$ test if the data were normally distributed and a non-parametric MannWhitney $U$ test when the distribution was skewed. Differences in the frequency of discrete variables between groups were assessed by the $\chi^{2}$ test with Yates' correction for small numbers where appropriate. For all analyses $\mathrm{p}<0.05$ was considered significant.

\section{Results}

Twenty one of the 90 patients gave a history of angina (New York Heart Association (NYHA) Grade I in five, grade II in 10, and grade III in six (table 1) and a further 12 had atypical chest pain. Five patients had had a previous myocardial infarction. Eighty eight had a calculated left ventricular mass index above the 97th percentile.

Table 3 Ambulatory ST segment monitoring

\begin{tabular}{lllll}
\hline & \multicolumn{3}{l}{ Symptoms } \\
\cline { 3 - 5 } ST depression segment & No of patients & Nil & Chest pain & Other \\
\hline Nil & 47 & 41 & 1 & 5 \\
Channel I & 27 & 19 & 5 & 2 \\
Channel II & 9 & 6 & 1 & 2 \\
Both channels & 7 & 5 & 1 & 1 \\
\hline
\end{tabular}

^Other symptoms recorded were arm pain (one), breathlessnes (six), and palpitations (three).
EXERCISE ELECTROCARDIOGRAPHY

Table 2 shows that of the 79 patients who underwent exercise electrocardiography 22 had no exercise induced electrocardiographic changes.

\section{Positive exercise electrocardiography}

Twenty six patients had ST segment depression of greater than $0.2 \mathrm{mV}$ in addition to the depression at rest. Fourteen patients had an increased number of leads showing ST segment depression and the $R$ wave response was abnormal in 40 patients. Twenty one patients fulfilled two of these criteria and two patients fulfilled all three.

\section{Other electrocardiographic changes}

Twelve patients had complete normalisation of their ST segments, 19 had a reduction in the number of leads showing ST segment depression, and 12 patients had exercise induced ventricular extrasystoles.

\section{Relation to symptoms}

The end point of exercise was chest pain in five patients, breathlessness in 11, leg fatigue in 42 , and general fatigue in 21 .

AMBULATORY ELECTROCARDIOGRAPHY

Table 3 shows that at the time of the monitoring period most patients had resting ST-T changes detectable on channel I. Only ST segment depression of greater than $0.2 \mathrm{mV}$ in addition to the resting value was, therefore, considered significant. By contrast, no patients had a resting electrocardiogram that showed ST segment depression in channel II.

Forty three patients had at least one episode of ST segment depression (as defined above) during the monitoring period. This was detected on channel $I$ in 27 patients, on channel II in nine patients, and on both channels in seven patients. The median number of episodes was 16 (range 1 to 84) with a median duration of 8.6 (range 2 to 17) min. Fourteen of the 27 patients with ST segment depression in channel I had accentuation of the resting ST segment depression. In the remaining 13 patients the pattern of ST segment depression changed.

\section{Relation to symptoms}

Eighteen patients recorded symptoms on the diary cards: chest pain was reported by eight, arm pain by one, breathlessness by six, and palpitation by three. In six of the patients who reported symptoms no abnormality was detected on ambulatory monitoring. Episodes of ST segment depression corresponded to symptoms in seven of the patients with chest pain, four with breathlessness, and one with palpitation. Over $90 \%$ of the episodes, however, were asymptomatic.

\section{THALLIUM PERFUSION SCINTIGRAPHY \\ Perfusion defects}

Small apical defects were present in 73 out of 80 patients and were presumably a reflection of the relative apical thinning ${ }^{19}$ that is exaggerated in the presence of left ventricular hypertrophy. There were abnormalities of perfusion in 
Table 4 Comparison of exercise haemodynamics and symptoms in patients with and without reversible thallium perfusion defects (mean (1SD))

\begin{tabular}{|c|c|c|c|c|}
\hline & \multicolumn{4}{|c|}{ Thallium perfusion defect } \\
\hline & Preser & & Absen & \\
\hline $\begin{array}{l}\text { Number } \\
\text { Exercise duration (min) } \\
\text { Peak heart rate (beats/min) } \\
\text { Peak systolic BP (mm Hg) } \\
\text { Double product }\end{array}$ & $\begin{array}{c}48 \\
3 \cdot 9 \\
121 \\
195\end{array}$ & $\begin{array}{l}(1 \cdot 7) \\
(23) \\
(31)\end{array}$ & $\begin{array}{c}32 \\
4 \cdot 6 \\
117 \\
209\end{array}$ & $\begin{array}{l}(2 \cdot 2) \\
(28) \\
(30)\end{array}$ \\
\hline $\begin{array}{l}\left(\mathrm{mm} \mathrm{Hg} \times \text { beats } / \min \times 10^{2}\right) \\
\text { Max predicted } \mathrm{MVO}_{2}(\%) \\
\text { Chest pain }(\mathrm{No}) \\
\text { Breathlessness }(\mathrm{No})\end{array}$ & $\begin{array}{c}238 \\
70 \\
5^{\star} \\
8\end{array}$ & $\begin{array}{l}(67) \\
(26)\end{array}$ & $\begin{array}{r}248 \\
79 \\
0 \\
3\end{array}$ & $\begin{array}{l}(85) \\
(29)\end{array}$ \\
\hline
\end{tabular}

${ }^{\star} \mathrm{p}<0.05$. RPD, reversible perfusion defect; $\mathrm{MVo}_{2}$, myo cardial oxygen consumption.

Table 5 Comparison of major risk factors in patients with and without coronary artery disease (mean (1 SD)

\begin{tabular}{|c|c|c|}
\hline & $\begin{array}{l}C A D \\
(n=18)\end{array}$ & $\begin{array}{l}N C A \\
(n=17)\end{array}$ \\
\hline $\begin{array}{l}\text { Age (y) } \\
\text { Smokers (No) } \\
\text { Duration of HBP (y) } \\
\text { SBP (mm Hg) } \\
\text { DBP (mm Hg) } \\
\text { Total cholesterol (mmol/l) } \\
\text { LDL cholesterol (mmol/l) } \\
\text { HDL cholesterol }(\mathrm{mmol} / \mathrm{l})\end{array}$ & $\begin{array}{cl}58 & (6 \cdot 4)^{\star} \\
13 & \\
7 \cdot 0 & (5 \cdot 2) \\
158 & (32) \\
90 & (16) \\
6.5 & (1 \cdot 1) \\
4 \cdot 4 & (0.9) \\
1 \cdot 2 & (0 \cdot 4)\end{array}$ & $\begin{array}{cl}51 & (8.9) \\
16 & \\
6 \cdot 2 & (8.9) \\
154 & (34) \\
94 & (20) \\
5.9 & (1.4) \\
3.7 & (1.4) \\
1.3 & (0.5)\end{array}$ \\
\hline
\end{tabular}

${ }^{\star} \mathrm{p}<0.05$. CAD, coronary artery disease; NCA, normal coronary arteries.

regions other than the apex in 64 patients. These perfusion defects were fixed in 16 and reversible in 48 patients.

\section{Relation to symptoms}

Exercise capacity in general was poor. The end point of exercise in those with reversible perfusion defects was leg fatigue in 20 , general fatigue in 15, breathlessness in eight, and chest pain in five patients. Table 4 shows that the exercise duration and haemodynamic function were similar in those with reversible perfusion defects and those without.

\section{CORONARY ANGIOGRAPHY}

Thirty five patients underwent coronary arteriography: 17 had normal coronary arteries and 18 had significant coronary artery disease. Of these, three had single, one had double, and 14 had triple vessel disease.

RELATION TO SYMPTOMS

Of the 18 patients with coronary artery disease seven gave no history of chest pain (five with triple vessel disease and two with single vessel disease). Eight had mild (NYHA I or II) angina and three had moderate (NYHA III) angina. Chest pain was also a complaint in five of the patients with normal coronary arteries, mild (NYHA II) in four, and moderate (NYHA III) in one. A complaint of breathlessness was equally common in the two groups (10 of those with coronary artery disease and eight of those with normal coronary arteries).

COMPARISON OF PATIENTS WITH AND WITHOUT CORONARY ARTERY DISEASE

Table 5 shows that the patients with coronary artery disease were older (mean (SD) 58 (6.4) $v$ $51(8.9)$ years, $95 \%$ confidence interval 1 to 12 years) but the blood pressure, serum cholesterol concentration, and smoking history were not significantly different. The duration of exercise and haemodynamics were also similar in the two groups.

\section{Usefulness of the non-invasive investigations} Table 6 gives the results of the non-invasive investigations for the 35 patients who had coronary arteriography and their sensitivity, specificity, positive predictive accuracy, negative predictive accuracy, and overall predictive accuracy.

\section{Discussion}

The similarity in the clinical course of patients with previous myocardial infarction and those with left ventricular hypertrophy and strain in the Framingham study has led to the suggestion that the electrocardiographic pattern typical of these conditions signified the onset of coronary artery disease. ${ }^{4}$ As only half of the patients in our study who had coronary arteriography had coronary artery disease, however, this cannot be the only explanation for the electrocardiographic finding. The absence of obstruction to the epicardial coronary arteries does not of course exclude myocardial ischaemia. In patients with left ventricular hypertrophy and normal coronary arteries, typical angina ${ }^{20-22}$ and objective signs of myocardial ischaemia ${ }^{23-26}$ are well recognised. In the present study chest pain and noninvasive indicators of myocardial ischaemia

Table 6 Accuracy of the non-invasive investigations in predicting the presence of coronary artery disease (figures based on the 35 patients who had coronary arteriography)

\begin{tabular}{|c|c|c|c|c|c|}
\hline & Sens (\%) & Spec (\%) & $P P A(\%)$ & $N P A(\%)$ & $O P A(\%)$ \\
\hline $\begin{array}{l}\text { Thallium scintigraphy: } \\
\text { RPD }\end{array}$ & 88.9 & 52.9 & $66 \cdot 6$ & $81 \cdot 8$ & $71 \cdot 4$ \\
\hline $\begin{array}{l}\text { Exercise ECG: } \\
\text { ST segment depression } \\
\text { Leads (No) } \\
\text { R wave }\end{array}$ & $\begin{array}{l}50 \\
33 \cdot 3 \\
44 \cdot 4\end{array}$ & $\begin{array}{c}70 \cdot 6 \\
100 \\
29 \cdot 4\end{array}$ & $\begin{array}{c}64 \cdot 3 \\
100 \\
40 \cdot 0\end{array}$ & $\begin{array}{l}57 \cdot 1 \\
58 \cdot 6 \\
33 \cdot 3\end{array}$ & $\begin{array}{l}60 \\
65 \cdot 7 \\
37 \cdot 1\end{array}$ \\
\hline $\begin{array}{l}\text { Two criteria } \\
\text { Three criteria }\end{array}$ & $\begin{array}{l}38 \cdot 9 \\
11 \cdot 1\end{array}$ & $\begin{array}{l}76 \cdot 5 \\
100\end{array}$ & $\begin{array}{c}63 \cdot 6 \\
100\end{array}$ & $\begin{array}{l}54 \cdot 2 \\
51 \cdot 5\end{array}$ & $\begin{array}{l}57 \cdot 1 \\
54 \cdot 3\end{array}$ \\
\hline $\begin{array}{l}\text { Ambulatory ECG: } \\
\text { Channel I } \\
\text { Channel II } \\
\text { Both }\end{array}$ & $\begin{array}{r}33.3 \\
11.1 \\
5.6\end{array}$ & $\begin{array}{l}64 \cdot 7 \\
70 \cdot 6 \\
76 \cdot 5\end{array}$ & $\begin{array}{l}50 \\
28 \cdot 6 \\
20 \cdot 0\end{array}$ & $\begin{array}{l}47 \cdot 8 \\
42 \cdot 9 \\
43 \cdot 3\end{array}$ & $\begin{array}{l}48 \cdot 6 \\
40 \\
40\end{array}$ \\
\hline
\end{tabular}

Sens, sensitivity; Spec, specificity; PPA, positive predictive accuracy; NPA, negative predictive accuracy; OPA, overall predictive accuracy; RPD, reversible perfusion defect. 
were present in five patients with left ventricular hypertrophy and normal coronary arteries. In total 43 patients had at least one episode of ambulatory ST segment depression consistent with myocardial ischaemia. As in a recent study of hypertensive patients with normal coronary arteries over $90 \%$ of these episodes were clinically silent. ${ }^{26}$

There are several factors that may be responsible for myocardial ischaemia in hypertensive left ventricular hypertrophy. There is a transmural gradient of blood flow in left ventricular hypertrophy with reduced flow in the subendocardial layers ${ }^{27}$ that is accentuated by pacing $^{28}$ and exercise. ${ }^{29}$ Although total myocardial blood flow is increased in left ventricular hypertrophy, the flow per $100 \mathrm{~g}$ is significantly reduced ${ }^{30}$ because of decreased coronary vascular reserve $\mathrm{e}^{31}$ and perhaps disease of the small vessels. $^{22}$

The ability of the coronary vasculature to maintain perfusion over a range of pressures may be altered by left ventricular hypertrophy. ${ }^{32}$ Because oxygen extraction is almost maximal in the coronary circulation there is no mechanism, as there is in the cerebral circulation, whereby the effects of lower perfusion pressures can be compensated for by an increase in oxygen extraction. ${ }^{33}$ This may be important during sleep when diastolic blood pressure often falls by up to $25 \% .{ }^{34}$ Certainly if the blood pressure is reduced by treatment to below the theoretical autoregulatory range, decreased coronary flow $^{35}$ and myocardial ischaemia $^{36}$ occur. Similar mechanisms have been proposed ${ }^{37}$ as a possible explanation for the excess mortality found in some studies (but these are disputed by several workers) if treated diastolic blood pressure falls below 85-90 $\mathrm{mm} \mathrm{Hg}$ - the so-called $\mathrm{J}$ shaped mortality curve. ${ }^{38}$ The results of the present study are compatible with these theories and they emphasise the importance of myocardial ischaemia in patients with hypertensive left ventricular hypertrophy even in the absence of epicardial coronary artery disease.

Another important clinical question is how best to identify prognostically important coronary artery disease in hypertensive patients with left ventricular hypertrophy and strain. This is particularly relevant because most of the myocardial ischaemia in this study did not cause symptoms. Ambulatory monitoring of the ST segment has been shown to be useful in detecting symptomatic and silent myocardial ischaemia in patients with ischaemic heart disease. ${ }^{1639} \mathrm{It}$ is a reproducible technique $^{40}$ and may provide prognostic information. ${ }^{41}$ In patients with left ventricular hypertrophy and strain, however, investigations that rely on the electrocardiogram are difficult to interpret because of baseline electrocardiographic abnormalities. For example in this study nearly all the patients who had ambulatory electrocardiographic monitoring showed ST segment depression in channel I for most of the day. For this reason an arbitrary criterion of $>0.2 \mathrm{mV}$ additional ST segment depression over and above the baseline depression was required before interpretation as a positive result. Another potential problem with ambulatory ST monitoring is the frequency of ST segment shift in normal subjects. ${ }^{42}$ It is likely that both these factors contributed to the low positive predictive accuracy $(28 \cdot 6-50 \%)$ of the ambulatory electrocardiography in the present study.

There were similar problems with the interpretation of the exercise electrocardiography. If conventional criteria ${ }^{11}$ had been used virtually all patients would have had a positive test. The high rate of false positive results in patients with abnormal control electrocardiograms is well known ${ }^{43}$ and we therefore decided to consider a change significant if there were changes additional to the resting ST segment depression, in order to improve the specificity of the test. ${ }^{13}$ Analysis of the $R$ wave amplitude with exercise may also improve the accuracy of exercise electrocardiography in patients with resting ST-T changes ${ }^{1214}$ and this was therefore incorporated into this study along with a comparison of the number of leads showing ST segment depression before and after exercise. The use of all these criteria combined resulted in $100 \%$ specificity but this was at the expense of sensitivity as only two patients with coronary artery disease had a test that was positive for all criteria $(11 \cdot 1 \%$ sensitivity). When sensitivity was improved by using only ST $(50 \%)$ or $R$ wave $(44.4 \%)$ criteria the specificity was reduced $(70 \cdot 6 \%$ and $29.4 \%$ respectively).

In our group of patients, thallium scintigraphy was the most useful method for the identification of coronary artery disease. The sensitivity was $88.9 \%$, which is comparable with reported series of patients with ischaemic heart disease in our hospital ${ }^{17}$ and elsewhere. ${ }^{44}$ The specificity of $52.9 \%$ was much less than for patients with ischaemic heart disease (89$97 \%) .{ }^{44}$ The discrepancy is presumably due to the presence of myocardial ischaemia despite normal coronary arteries.

It is not possible from our results to determine whether the "false" positive non-invasive tests are such or are actually correctly identifying areas of ischaemia caused by left ventricular hypertrophy even in the absence of coronary artery disease. Two studies published recently, however, accord with our own results suggesting that the non-invasive findings are caused by myocardial ischaemia in these patients. ${ }^{2645} \mathrm{In}$ terms of excluding epicardial coronary artery disease the negative predictive accuracy is perhaps the most useful criterion to assess the value of the test. Our results showing a negative predictive accuracy of $81.8 \%$ accord with those of Tubau et al who reported that over a 38 month period of follow up the negative predictive value of thallium scintigraphy for the subsequent development of angina symptoms was $94 \%{ }^{46}$

In summary, our results have shown that not all patients with left ventricular hypertrophy and strain have obstructive coronary artery disease. Non-invasive indicators of myocardial ischaemia are common in patients with left ventricular hypertrophy and strain even in those without symptoms or coronary artery 
disease. Symptoms of chest pain during exercise or during normal daily activities are poor indicators of the presence of myocardial ischaemia and much of this ischaemia is silent. Thallium perfusion scintigraphy is a useful investigation for the identification of coronary artery disease in these patients.

One of us (SDP) was supported by a British Heart Foundation junior research fellowship.

1 Kannel WB, Gordon T, Castelli WP, Margolis JR. Electrocardiographic left ventricular hypertrophy and risk of coronary heart disease: The Framingham Study. $A n n$ Intern Med 1970;72:813-22.

2 Kannel WB. Prevalence and natural history of electrocardiographic left ventricular hypertrophy. Am J Med 1983;75 (suppl 3A):4-11.

3 Dunn FG, McLenachan J, Isles CG, et al. Left ventricular hypertrophy and mortality in hypertension: an analysis of data from the Glasgow Blood Pressure Clinic. J Hypertens 1990;8:775-82.

4 Kannel WB, Abbott RD. A prognostic comparison of left ventricular hypertrophy and unrecognised myocardial infarction: The Framingham Study. Am Heart J 1986; 111:391-7.

5 Macfarlane PW. British Regional Heart Study: the electrocardiogram and risk of myocardial infarction on followup. J Electrocardiol 1987;20 (suppl):53-6.

6 Pringle SD, Macfarlane PW, McKillop JH, Lorimer AR, Dunn FG. Pathophysiological assessment of left ventricular hypertrophy and strain in asymptomatic patients with essential hypertension. J Am Coll Cardiol 1989;13:1377-81.

7 Macfarlane PW, Watts MP, Podolski M, Shoat D, Lawrie TDV. The new Glasgow system. In: Willems JL, van Bemmel JH, Zyweitz C, eds. Computer ECG analysis: towards standardisation. Amsterdam: Elsevier, 1986:31-6.

8 Devereux RB, Reichek N. Echocardiographic determination of left ventricular mass in man: anatomic validation of the of left ventricular mass in man: anat
method. Circulation 1977;55:613-8.

9 Astrand I. Aerobic work capacity in men and women with special reference to age. Acta Physiol Scand 1960;49(suppl 169): $45-60$

10 Bruce RA, Kusumi F, Hosmer D. Maximal oxygen intake and nomographic assessment of functional aerobic impairment in cardiovascular disease. Am Heart $J$ 1973;85: 546-62.

11 Martin CM, McConachy DR. Maximal treadmill exercise electrocardiography. Correlations with coronary arteriography and cardiac haemodynamics. Circulation 1972;46: graphy 62 .

12 Yiannikas J, Marcomichelakis J, Taggart P, Kelly BH, Emanuel $\mathbf{R}$. Analysis of exercise-induced changes in $\mathbf{R}$ wave amplitude in asymptomatic men with electrocardiographic ST-T changes at rest. Am J Cardiol 1981; 4iographic

13 Kansal S, Roitman D, Sheffield LT. Stress testing with ST segment depression at rest. Circulation 1976;54:636-9.

14 Bonoris PE, Greenburg PS, Cristison GW, Castellanet MJ Ellestad MH. Evaluation of $R$ wave amplitude changes versus ST-segment depression in stress testing. Circulation 1978;57:904-10.

15 Macfarlane PW, McLung JM, Irving A, Watts MP, Taylor TP, Lawrie TDV. Computer assisted analysis of dynami (24-hour) electrocardiograms. In: Macfarlane PW, ed. Progress in electrocardiology. London: Pitman, 1979. 123-6.

16 Mulcahy D, Keegan J, Cunningham D, et al. Circadian variation of total ischaemic burden and its alteration with anti-anginal agents. Lancet 1988;ii:755-9.

17 Martin W, Tweddel AC, McGhie AI, Hutton I. Gated thallium scintigraphy in patients with coronary artery thallium scintigraphy in patients with coronary artery
disease: an improved planar imaging technique. Clin Phys Physiol Meas 1987;8:343-54.

18 Swinscow TDV. Statistics at square one. 8th ed. Plymouth: Latimer and Trend, 1987.

19 Bradfield JWB, Beck G, Vecht RJ. Left ventricular apical thin point. Br Heart $1977 \cdot 39 \cdot 806-9$.

20 Baxter RH, Reid JM, McGuiness JB, Stevenson JG. Relation of angina to coronary artery disease in mitral and in aortic valve disease. $B r$ Heart $J$ 1978;40:918-22.

21 Marcus ML, Doty DB, Hiratzka LF, Wright CB, Eastham
CL. Decreased coronary reserve. A mechanism for angina pectoris in patients with aortic stenosis and normal coronary arteries. N Engl J Med 1982;307:1362-7.

22 Mosseri M, Yarom R, Gotsman MS, Hasin Y. Histological evidence for small vessel coronary artery disease in patients with angina and patent large coronary arteries. Circulation 1986;74:964-72.

23 Bailey IK, Come PC, Kelly DT, et al. Thallium-201 myocardial perfusion imaging in aortic valve stenosis. $\mathrm{Am}$ J Cardiol 1977;40:889-99.

24 McKillop JH, Murray RG, Turner JG. Thallium-201 imaging in aortic valve disease. Nuklearmedizin 1979; imaging in aortic

25 Nagata S, Park Y, Minamikawa T, et al. Thallium perfusion and cardiac enzyme abnormalities in patients with familial and cardiac enzyme abnormalities in patients with familial hypertrop

26 Scheler S, Motz W, Vester J, Strauer BE. Transient myocardial ischaemia in hypertensive heart disease. $\mathrm{Am} \mathrm{J}$ Cardiol 1990;65:51G-5G.

27 Rembert JC, Kleinman LH, Fedor JM, Wechsler AS, Greenfield Jr JC. Myocardial blood flow distribution in concentric left ventricular hypertrophy. J Clin Invest 1978;62:379-86.

28 Mueller TM, Marcus ML, Kreber RE, Young JA, Barnes RW, Abboud FM. Effects of renal hypertension and left ventricular hypertrophy on the coronary circulation in dogs. Circ Res 1978;4:543-9.

29 Murray PA, Vatner SF. Abnormal coronary vascular response to exercise in dogs with severe right ventricular ponse to exercise in dogs with severe right
hypertrophy. $J$ Clin Invest 1981;67:1314-23.

30 Johnson LL, Sciacca RR, Ellis K, Weiss MB, Cannon PJ. Reduced left ventricular myocardial blood flow per unit mass in aortic stenosis. Circulation 1978;57:582-90.

31 Strauer B. Ventricular function and coronary hemodynamics in hypertensive heart disease. Am J Cardiol 1979; 44:999-1006.

32 Harrison DG, Florentine MS, Brooks LA, Cooper SM, Marcus ML. The effect of hypertension and left ventricular hypertrophy on the lower range of coronary autoregulation. Circulation 1988;77:1108-15.

33 Strangaard S, Haunso $S$. Why does antihypertensive treatment prevent stroke but not myocardial infarction? Lancet 1987; ii:658-61.

34 Miller-Craig MW, Bishop CN, Raftery EB. Circadian variation of blood pressure. Lancet 1978;i:595-7.

35 Laskey WH, Zeevi GR, St John Sutton M, Martin JL, Hirshfeld JW, Reichek N. Effects of nitroglycerin in patients with angina, normal coronary arteries, and left patients with angina, normal coronary arteries, and left
ventricular hypertrophy. Am Heart $J$ 1986;112:953-62.

36 Pepi M, Alimento M, Maltagliati A, Tosi E, Guazzi MD. Pepi $M$, Alimento $M$, Maltagliati A, Tosi E, Guazzi $M D$. injury elicited by rapid pressure lowering in hypertension. Eur Heart J 1988;9:889-905.

37 Floras JS. Antihypertensive treatment, myocardial infarction and nocturnal myocardial ischaemia. Lancet 1988;ii: $994-6$.

38 Cruickshank JM. Coronary flow reserve and the J curve relation between diastolic blood pressure and myocardial infarction. $B M J$ 1988;297:1227-30.

39 Deanfield JE, Maseri A, Selwyn AP, et al. Myocardial ischaemia during daily life in patients with stable angina: its relation to symptoms and heart rate changes. Lancet its relation to

40 Khurmi NS, Raftery EB. Reproducibility and validity of ambulatory ST segment monitoring in patients with chronic stable angina pectoris. Am Heart $J$ 1987;113: 1091-6.

41 Stern $S$, Tzivoni $D$. Early detection of silent ischaemic heart disease by 24-hour electrocardiographic monitoring of active subjects. Br Heart $J$ 1974;36:481-6.

42 Kohli RS, Cashman PMM, Lahiri A, Raftery EB. The ST segment of the ambulatory electrocardiogram in a normal population. Br Heart J 1988;60:4-16.

43 Harris CN, Aronow WS, Parker DP, Kaplan MA. Treadmill stress test in left ventricular hypertrophy. Chest 1973; 63:353-7.

44 Stolzenberg J, London R. Stress thallium-201 scanning in coronary artery disease. Med Clin North Am 1980;64: $149-62$.

45 Yureney AP, de Ouattro V, Devereux RB. Hypertensive heart disease: relationship of silent ischemia to coronary artery disease and left

46 Tubau JF, Szlachcic J, Hollenberg M, Massie BM. Usefulness of Thallium-201 scintigraphy in predicting the development of angina pectoris in hypertensive patients with left ventricular hypertrophy. Am J Cardiol 1989; 64:45-9. 